\title{
Establishment of a New Global Grid Weighted Mean Temperature Model Based on Surface Temperature
}

\author{
Hongmin Zhang ${ }^{1, ~ a ~}$, and Zhangyu Sun ${ }^{1, b}$ \\ ${ }^{1}$ School of Geodesy and Geomatics, Wuhan University, Wuhan 430079, China. \\ 1565503313@qq.com, ${ }^{b} 1753814280 @ q q . c o m$
}

Keywords: GNSS; PWV; $T_{m}$; global grid model.

\begin{abstract}
Weighted mean temperature $\left(T_{m}\right)$ is a critical parameter in Global Navigation Satellite System (GNSS) technology to retrieve precipitable water vapor (PWV). In this study, a new global grid $T_{m}$ model based on surface temperature $\left(T_{s}\right)$ called GTSC-Tm was built. The precision of the newly built model was validated using the European Centre for Medium-Range Weather Forecasts (ECWMF) ERA-Interim data and the radiosonde data. Another three existing $T_{m}$ models, including the Bevis linear regression formula, the GTm model and the GPT2w model, were employed for comparisons. Results show that when tested with the ERA-Interim data, the average root mean square (RMS) of the GTSC-Tm is $2.06 \mathrm{~K}$, showing precision improvements of approximately $46 \%, 24 \%$ and $36 \%$ compared with the Bevis, GTm and GPT2w model. When tested with the radiosonde data, the GTSC-Tm has an average RMS of $3.53 \mathrm{~K}$ with the accuracy improvements of approximately 13\%, 10\% and 8\% compared with the Bevis, GTm and GPT2w model.
\end{abstract}

\section{Introduction}

$T_{m}$ is a crucial parameter in the PWV retrieval process using GNSS technology, since its accuracy can directly influence the precision of retrieved PWV [1]. Previous studies have established various $T_{m}$ models. Generally, there are two types of $T_{m}$ models. The first is the $T_{s}$-based model, which is based on the linear relationship between $T_{m}$ and $T_{s}$ found by Bevis in 1992. The second is the empirical model, which only requires the day of year, the latitude, longitude and altitude of the GNSS station as the input parameters. One of the widely used empirical models is the GPT2w model developed in literature [2]. However, there are some limitations in both of them. For the $T_{s}$-based model, according to the study results of literature [3], the $T_{s}-T_{m}$ correlation is weak in the tropic areas. Moreover, some $T_{s}$-based models applicable for one specific region cannot be applied to another region. For the empirical model, the $T_{m}$ time series derived from it are always "too smooth", thus not be able to capture the sudden changes or spike-shaped peaks. Considering the limitations, a new global grid $T_{m}$ model based on $T_{s}$ was built in this paper, in expectation to compensate the limitations and acquire higher precision. 


\section{Experimental Data}

\subsection{ERA-Interim Data.}

The global atmospheric reanalysis product ERA-Interim was published recently by ECMWF, which has higher quality than that of the previous ERA-40 data [4]. Since the reanalysis provide meteorological data in a grid form, it is suitable for building grid model. The ERA-Interim offers data with the highest spatial resolution of $0.125^{\circ}$ and the highest temporal resolution of 6 hours, which can be downloaded for free online.

\subsection{Radiosonde Data.}

The radiosonde data originates from the radiosonde dataset of the National Climate Data Center (NCDC), which can be obtained via Integrated Global Radiosonde Archive (IGRA). IGRA includes high-quality observational data derived from more than 1500 radiosondes and sounding balloons from the 1960s, and users can download it for free online. The radiosonde data provide the temperature, geopotential and water vapor pressure profiles two times each day. In this study, 678 radiosonde stations distributed globally were selected, the distribution of which is shown in Fig. 1.

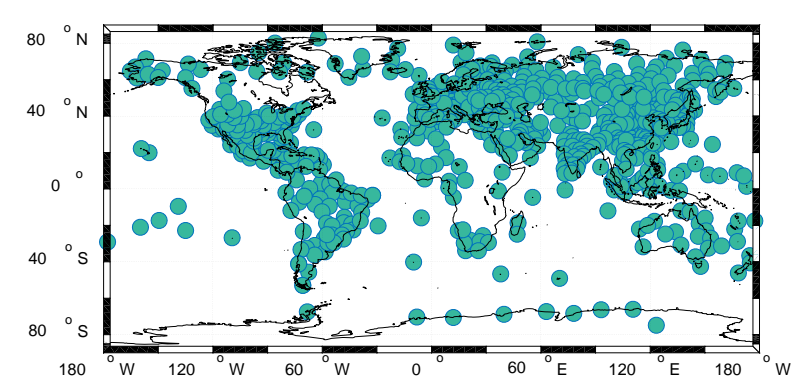

Fig. 1 The distribution of the selected 678 radiosonde stations.

\section{Modeling Process}

Several studies have proved that the relation between $T_{m}$ and $T_{s}$ is regional and location-based [5,6]. The grid modeling method establishes model by storing the model coefficients at each grid point. It is true that the coefficient of each grid point can exhibit the regional trait of the area around this grid point. Therefore, though the grid model is a global model, it can reflect the regional characteristics with high accuracy and high spatial resolution. Furthermore, literature [7] studied the residuals of the $T_{s}$-based model and found that the residuals show a high correlation with time. For eliminating such residuals, the trigonometry function with an annual cycle and a semi-annual cycle was used to model them. Consequently, the expression of the model formula is shown as:

$$
\begin{aligned}
T_{m}= & b \cdot T_{s}+a_{0}+\Delta T_{m} \\
\Delta T_{m}= & a_{1} \cdot \cos \left(\frac{d o y}{365.25} 2 \pi\right)+a_{2} \cdot \sin \left(\frac{d o y}{365.25} 2 \pi\right)+ \\
& a_{3} \cdot \cos \left(\frac{d o y}{365.25} 4 \pi\right)+a_{4} \cdot \sin \left(\frac{d o y}{365.25} 4 \pi\right)
\end{aligned}
$$


Where $T_{s}$ denotes the surface temperature $(\mathrm{K}), \Delta T_{m}$ denotes the $T_{m}$ residual $(\mathrm{K})$, doy denotes the day of year, $b$ denotes the scaling coefficient, $a_{0}$ denotes the translation coefficient, $\left(a_{1}, a_{2}\right)$ and $\left(a_{3}\right.$, $a_{4}$ ) respectively denote the annual and semi-annual amplitudes of residual.

The grid $T_{m}$ derived from the ERA-Interim pressure levels data of three years (2013 2015) were used to determine the model coefficients. Literature [8] has proved that high-accuracy $T_{s}$ can be derived from ERA-Interim data. In this study, the $T_{s}$ series of three years were also obtained from the ERA-Interim data. The least squares method was used to calculate the model coefficients at each grid point on a global scale with a spatial resolution of $2.5^{\circ}$. The model built is called GTSC-Tm.

When we are going to calculate the $T_{m}$ at the location of a GNSS user, the $T_{s}$ is required, which can be obtained either from temperature sensors, radiosonde data, reanalysis data or empirical models. The coefficients of four grid points closest to the GNSS user are used to calculate the coefficients of the GNSS user's location employing bilinear interpolation methodology. Then, the $T_{m}$ at the surface level can be derived using eq. (1) and eq. (2) with $T_{s}$. If the location of the GNSS user is not at the surface level, a $T_{m}$ lapse rate of $-5.1 \mathrm{~K} / \mathrm{km}$ is used for the vertical correction [9].

\section{Validation of the Model}

\subsection{Tested with the ERA-Interim Data.}

To validate the GTSC-Tm, the $T_{m}$ series of 2016 derived from the ERA-Interim data were used as references. The $T_{m}$ estimations derived from the GTSC-Tm model were compared with the references. The $T_{m}$ estimations derived from the Bevis linear regression formula [1], the GTm model [3] and the GPT2w model [2] were used for comparisons. The $T_{s}$ values needed were also obtained from the ERA-Interim data. The global distributions of RMSs are shown in Fig. 2. According to Fig 2, large uncertainties can be observed in the ice-covered areas (e.g. the Antarctic, the Qinghai-Tibetan Plateau and the Greenland) of the Bevis model. The precision of the GTm model is higher than that of the Bevis model, while large uncertainties can still be observed in some areas. The GPT2w model has higher precision in the oceanic areas than in the continental areas. When $T_{m}$ estimations are obtained from the GTSC-Tm model, the RMSs are small globally and no large uncertainties can be observed. According to the statistics, the average RMSs of the Bevis, GTm and GPT2w model are respectively 3.80 K, 2.70 K, and 3.19 K. Nevertheless, the GTSC-Tm model has the average RMS of only $2.06 \mathrm{~K}$, achieving the precision improvements of approximately 46\%, 24\% and 36\% compared with the Bevis, GTm and GPT2w model.
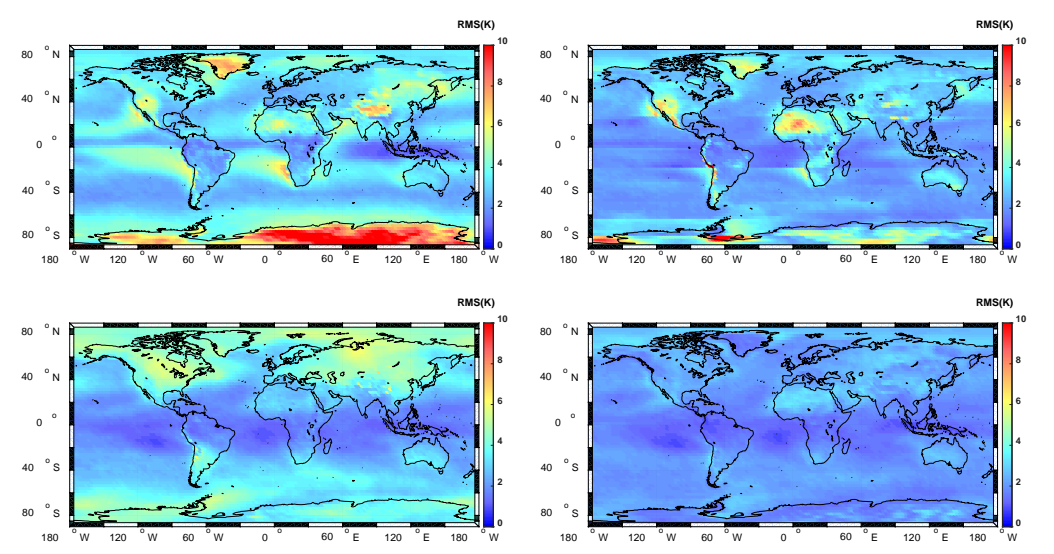

Fig. 2 Global distributions of RMSs of different models tested with the ERA-Interim data 


\subsection{Tested with the Radiosonde Data.}

For further validation, the radiosonde data of 2016 from the 682 radiosonde stations were used to obtain $T_{m}$ values, which were used as references. The $T_{m}$ estimations derived from the Bevis formula, the GTm model, the GPT2w model, and the GTSC-Tm model were compared with the references. The $T_{s}$ values were derived from the radiosonde data. The RMSs of the 678 radiosonde stations were calculated and integrated according to the latitude band (20 is a latitude band). The average RMSs of different models in each latitude band are shown in Fig. 3. Furthermore, for observing the accuracies in different times, monthly statistics of the RMSs of the 678 radiosonde stations were conducted. The average RMSs of the twelve months in 2016 are also shown in Fig. 3.
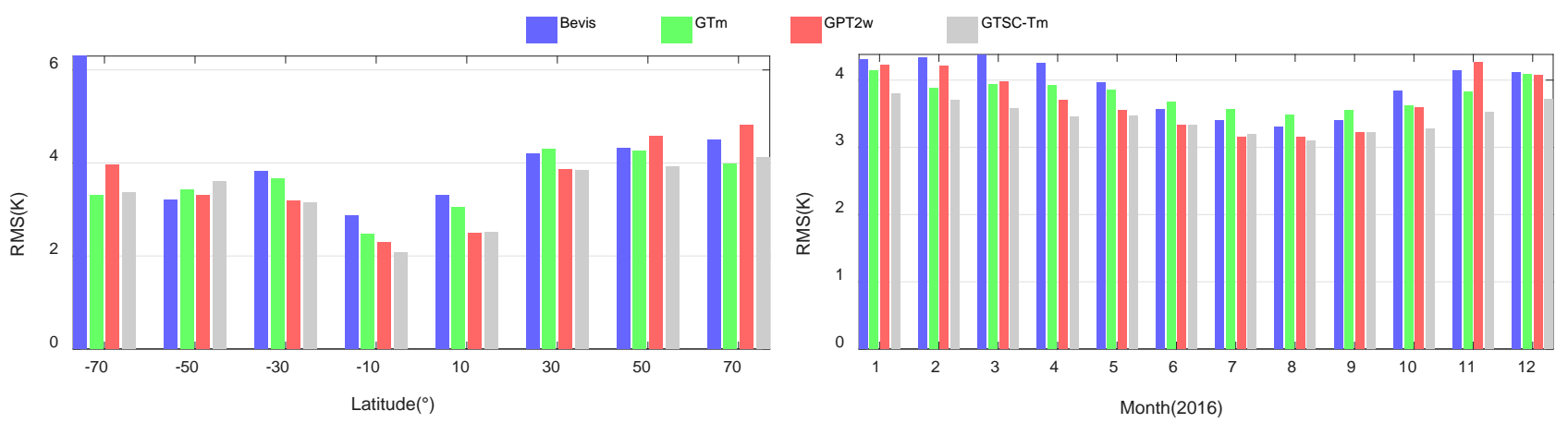

Fig. 3 Average RMSs of different models in different latitude bands and different months tested with the radiosonde data.

As can be seen in Fig. 3, the precision of the $T_{m}$ estimations is low in the low-latitude regions and high in the high-latitude regions. The average RMS of the GTSC-Tm model is slightly larger than the other three models in the latitude band of $60^{\circ} \mathrm{S} \sim 40^{\circ} \mathrm{S}$, whereas in the other latitude bands, the GTSC-Tm model exhibits the highest precision among these four models, as in some latitude bands, the accuracy of the GTSC-Tm model may be comparable to that of another one model. With reference to the seasonal analysis, the precision of the $T_{m}$ estimations in summer is higher than that in winter. The GTSC-Tm model has the smallest RMS along the whole year among these four models, while its precision is comparable to that of the GPT2w model in summer. According to the statistics, the GTSC-Tm model has an average RMS of $3.53 \mathrm{~K}$ with the accuracy improvements of approximately $13 \%, 10 \%$ and $8 \%$ compared with the Bevis, GTm and GPT2w model, the average RMSs of which are respectively $4.03 \mathrm{~K}, 3.89 \mathrm{~K}$ and $3.81 \mathrm{~K}$.

\section{Conclusion}

Considering the limitations existing in the state-of-art $T_{m}$ models, this paper built a new global grid $T_{m}$ model based on $T_{s}$ called GTSC-Tm using the ERA-Interim data. Then, another dataset of the ERA-Interim data and the radiosonde data were used to validate this newly built model. Another three state-of-art $T_{m}$ models (the Bevis, GTm and GPT2w model) were employed for comparisons. Validation results show that when tested with the ERA-Interim data, the average RMS of the GTSC-Tm model is $2.06 \mathrm{~K}$ with the precision improvements of approximately $46 \%$, 24\% and 36\% compared with the Bevis, GTm and GPT2w model. And when tested with the radiosonde data, the average RMS of the GTSC-Tm models is $3.53 \mathrm{~K}$. The precision improvements compared with the Bevis, GTm and GPT2w model are approximately 13\%, 10\% and 8\%. 


\section{References}

[1] Bevis M, Businger S, Herring TA, Rocken C, Anthes RA, Ware RH (1992) GPS meteorology: remote sensing of atmospheric water vapor using the global positioning system. J Geophys Res 97(D14):15787-15801.

[2] Böhm, J., G. Möller, M. Schindelegger, G. Pain, and R. Weber (2014), Development of an improved empirical model for slant delays in then troposphere (GPT2w), GPS Solut., doi:10.1007/s10291-014-0403-7.

[3] Yao Y, Zhang B, Xu C, Chen J (2014a) Analysis of the global $T_{m}-T_{s}$ correlation and establishment of the latitude-related linear model. Chin Sci Bull 59(19):2340-2347.

[4] Simmons, A., S. Uppala, D. Dee, and S. Kobayashi (2007), ERA-Interim: New ECMWF reanalysis products from 1989 onwards, ECMWF Newsl.,110, 25-35.

[5] Ross, R. J., and S. Rosenfeld (1997), Estimating mean weighted temperature of the atmosphere for Global Positioning System applications, J. Geophys. Res., 102, 21,719-21,730.

[6] Wang, J., L. Zhang, and A. Dai (2005), Global estimates of water-vapor-weighted mean temperature of the atmosphere for GPS applications, J. Geophys. Res., 110, D21101, doi:10.1029/2005JD006215.

[7] Yao, Y. B., Zhang, B., Xu, C. Q., and Yan, F.: Improved one/multi-parameter models that consider seasonal and geo-graphic variations for estimating weighted mean temperature in ground-based GPS meteorology, J. Geodesy, 88, 273-282.

[8] Dee, D., S. Uppala, A. Simmons, P. Berrisford, P. Poli, S. Kobayashi, U. Andrae, M. Balmaseda, G. Balsamo, and P. Bauer (2011), The ERA-Interim reanalysis: Configuration and performance of the data assimilation system, Q. J. R. Meteorol. Soc., 137, 553-597.

[9] Yao, Y., C. Xu, B. Zhang, and N. Cao (2014), GTm-III: A new global empirical model for mapping zenith wet delays onto precipitable water vapour, Geophys. J. Int., 197(1), 202-212, doi:10.1093/gji/ggu008. 